\title{
Relationships between stress, social support and transactive memory among humanitarian aid workers
}

\section{Célia Blanchet* and Estelle Michinov}

\author{
Department of Psychology, CRPCC (E.A. 1285), \\ University of Rennes 2, \\ Place du recteur Henri Le Moal, \\ CS 24307, 35043 Rennes cedex, France \\ E-mail: celia.blanchet@univ-rennes2.fr \\ E-mail: estelle.michinov@univ-rennes2.fr \\ ${ }^{*}$ Corresponding author
}

\begin{abstract}
This study examines coordination processes (transactive memory) among humanitarian aid workers, and the relationships between stress, social support and transactive memory. Sixty humanitarian aid workers from non-governmental organisations completed a questionnaire. The measures included scales of transactive memory, perceived stress, compassion fatigue and social support. Data from partial least squares (PLS) showed that transactive memory is not structured identically among stable teams and humanitarian aid teams: transactive memory is essentially based on tacit coordination processes among humanitarian aid workers. The results showed that stress was negatively related to transactive memory and that social support was positively related to it. Moreover, social support was not a moderator of the relationship between stress and transactive memory. This study highlights the need to develop programmes to prepare humanitarian aid workers for the management of emergency situations and to protect them from stress.
\end{abstract}

Keywords: emergency; humanitarian aid workers; social support; stress; team coordination; transactive memory.

Reference to this paper should be made as follows: Blanchet, C. and Michinov, E. (2014) 'Relationships between stress, social support and transactive memory among humanitarian aid workers', Int. J. Emergency Management, Vol. 10, Nos. 3/4, pp.259-275.

Biographical notes: Célia Blanchet is a Doctoral student in the Department of Psychology at the University of Rennes 2. She holds a Master's degree in Psychology from the University of Rennes 2. Her thesis concerns coordination processes and stress in unstable teams.

Estelle Michinov is a Professor of Social Psychology at the University of Rennes 2. Her research deals with team coordination (medical teams, emergency teams, virtual teams, crisis units and multidisciplinary networks), interpersonal relationships, well-being and health, and performance. She lectures in dynamic groups and performance, social psychology and organisational psychology. 


\section{Introduction}

In recent years, many large-scale disasters have occurred: natural disasters such as Hurricanes Katrina and Rita in 2005, Cyclone Nargis, which devastated parts of Myanmar in 2008, the earthquakes in Haiti (2010) and Japan (2011), or man-made disasters such as the terrorist attacks of 11 September 2001. In such chaotic and complex environments, disaster researchers have recognised the decisive role of coordination among humanitarian aid workers for the management of emergency situations (e.g., Drabek and McEntire, 2003; Majchrzak et al., 2007; Stephenson, 2005).

However, many factors contribute to coordination difficulties in emergency humanitarian actions. First, non-governmental organisations engage a large number of actors. They come to work in a foreign country with different missions, interests and expertise, and also with diverse backgrounds (e.g., different cultures, languages and organisational practices). All these factors, together with geographic dispersion, can make communication and coordination difficult (Carlile, 2002; Majchrzak et al., 2007). Second, the work environment of emergency humanitarian aid teams changes constantly: it is unstable, unpredictable and uncertain (Majchrzak et al., 2007; Yanay et al., 2011). Third, emergency humanitarian aid means urgency and time pressure. These features necessitate the ability to adapt and to be flexible, with significant implications: less predetermined structures; less stable tasks, roles and expertise and less hierarchical organisation with weakness of formal coordination protocols (Drabek and McEntire, 2003; Majchrzak et al., 2007; Tierney et al., 2001). This volatility in humanitarian aid teams may affect coordination efforts. Fourth, humanitarian aid workers are susceptible to developing a high level of stress (Bierens de Haan et al., 2002; Musa and Hamid, 2008), which has a negative impact on coordination processes (Driskell and Salas, 1991; Driskell et al., 1999; Ellis, 2006; Entin and Serfaty, 1999). Because of these characteristics, humanitarian aid workers must adopt specific approaches to team coordination (Majchrzak et al., 2007; Stephenson, 2005).

The above-mentioned conclusion leads to a number of very important issues about coordination. What are the specific features of emergency humanitarian aid teams' coordination? How can the knowledge and expertise of different actors be brought together in humanitarian emergency teams? Which factors affect coordination processes in humanitarian aid teams? This is a research area of importance both theoretically for the management of emergency situations and practically to ensure disaster preparedness of humanitarian aid workers. Indeed, coordination in humanitarian emergency teams is critical if they are to respond effectively to disasters. However, "we still lack much insight into the internal dynamics of these emergent organisations" (Drabek, 1986, p.161).

A number of recent studies have been conducted to examine how teams can develop emergent collaborative processes (Faraj and Sproull, 2000; Faraj and Xiao, 2006; Majchrzak et al., 2007; Rico et al., 2008). In volatile environments with high levels of uncertainty and stress, coordination processes appear to be highly dependent on the shared or mutual mental models of team members (Leedom and Simon, 1995; Serfaty and Entin, 1977; Yanay et al., 2011) and particularly on transactive memory systems (TMSs) (Faraj and Xiao, 2006; Majchrzak et al., 2007). 


\section{Literature review}

\subsection{Principles of transactive memory theory}

Transactive memory is defined as "a shared system for encoding, storing and retrieving selectively information" (Wegner et al., 1991, p.923). Transactive memory is presented as a form of shared cognition (e.g., Moreland, 1999; Resnick et al., 1991), whereby team members are aware of the location of expertise within the group, and the accuracy of this information is consensual. Transactive memory is composed of individual memories and TMSs. TMS is a set of knowledge shared by all the group members about 'who knows what' (a shared conceptualisation of the knowledge of each group member). Within such a system, a specialisation of knowledge is developed (Wegner, 1987); members do not each need to memorise all the information required for task success but only the information depending on his or her own area of knowledge. The development of TMS within the team provides its members with greater specialisation in specific knowledge areas, greater belief in co-workers' expertise, and a better ability to work together efficiently (Lewis, 2003; Michinov, 2007; Moreland and Argote, 2003). Sharing the responsibility and delivery of expertise allows knowledge to be increased within the group, leading to improved results (Liang et al., 1995; Moreland et al., 1996; Moreland and Myaskovsky, 2000) and decision-making processes (Hollingshead, 1998).

\subsection{Extension of transactive memory theory to humanitarian aid teams}

Transactive memory theory has largely been used to explain knowledge sharing among stable groups or teams, with a number of preconditions known to facilitate expertise coordination: "shared goals; a clear reward structure; known group membership, expertise and skills to accomplish the task and time to share who knows what" (Majchrzak et al., 2007, p.149). However, these features do not exist in humanitarian aid teams that have to face high levels of urgency, unpredictability and re-configurability. For example, the composition of humanitarian aid teams changes constantly. Consequently, members may refuse to rely on the knowledge of their co-workers and be unwilling to learn about their expertise. Because members are unfamiliar with each other's perspectives and skills, it is more difficult for them to accept their expertise and suggestions than in permanent teams, which may cause expertise integrative tension. Working alongside people with different motives and objectives and whom they do not entirely trust, group members may feel less inclined to share their opinions and manage task conflicts (Halbesleben, 2006; Jehn et al., 1999). In sum, these characteristics of humanitarian aid teams may hinder the development of TMSs. Nevertheless, transactive memory theory can be extended to the emergent response group (Majchrzak et al., 2007). Although some researchers have recently applied transactive memory to large and volatile groups (Ren et al., 2006) and interdisciplinary teams (e.g., Akgün et al., 2006; Faraj and Xiao, 2006), no empirical studies have specifically investigated the structure and antecedents of transactive memory in humanitarian aid teams.

The aim of this study was to examine transactive memory among emergency humanitarian aid workers and, especially, the relationships between stress and tacit coordination processes such as transactive memory. 


\subsection{Stress among humanitarian aid workers}

Humanitarian aid teams are associated with uncertainty, ambiguity and time pressure (Yanay et al., 2011). Humanitarian aid workers are also frequently exposed to multiple stressors in their day-to-day activity (Bierens de Haan et al., 2002; Ehrenreich and Elliot, 2004; Eriksson et al., 2009; Musa and Hamid, 2008; Prati et al., 2010; Vergara and Gardner, 2011) because of the hostile and difficult work environment (i.e., traumatic events, contact with people in distress, role ambiguity, task and environment unpredictability, high workload, team conflict, difficult living conditions or lack of resources). These stressors can lead to various forms of stress, including burnout, compassion fatigue and secondary traumatisation and post-traumatic stress disorder (see Antares Foundations, 2006; Ehrenreich and Elliot, 2004; Figley, 1995; Stamm, 1995; Yanay et al., 2011). Two major types of stress have been associated with humanitarian aid work: Generic Stress (Bierens de Haan et al., 2002) and Compassion Fatigue (Figley, 1995; Musa and Hamid, 2008; Stamm, 2010). Generic stress is defined as "an individual's psychological response to a situation in which there is something at stake for the individual and where the situation taxes or exceeds the individual's capacity or resources" (LePine et al., 2004, p.883). Generic stress is often related to difficult living situations and environmental stressors, management issues and team conflict. Compassion fatigue refers to the cost of caring (Figley, 1995) and "is characterised by the negative aspects of providing care to those who have experienced extreme or traumatic stressors" (Stamm, 2010, p.21). Compassion fatigue splits into two parts: secondary traumatic stress and burnout (Stamm, 2010). Secondary traumatic stress is about "workrelated, secondary exposure to people who have experienced extremely or traumatically stressful events" (Stamm, 2010, p.13). Burnout "is associated with feelings of hopelessness and difficulties in dealing with work or in doing the job effectively" (Stamm, 2010, p.13).

A number of studies have demonstrated the negative effects of stress on coordination processes in teams (Driskell and Salas, 1991; Driskell et al., 1999; Ellis, 2006; Entin and Serfaty, 1999). In a situation assessed as threatening, team members move from a team-focused to a person-focused perspective (Driskell et al., 1999); their attention narrows, and peripheral task cues such as interpersonal activities (e.g., communication, coordination) are ignored to focus on central task cues. They are unmotivated and unwilling to learn about each other's roles and knowledge areas (LePine et al., 2004; Pearsall et al., 2009) and consequently find it difficult to trust each other and coordinate their actions. This shift in attention away from the team disrupts the informationprocessing system by narrowing attention to central task cues (e.g., Driskell et al., 1999), with less time spent on team activities such as communication, coordination and pursuit of shared knowledge, including mental models and transactive memory (Ellis, 2006; Pearsall et al., 2009).

On the basis of these studies suggesting the negative impact of stress on coordination processes in teams, we expected to observe a negative relationship between stress and transactive memory among humanitarian aid workers.

Hypothesis 1a: Generic stress would be negatively related to transactive memory among humanitarian aid workers.

Hypothesis 1b: Compassion fatigue would be negatively related to transactive memory among humanitarian aid workers. 


\subsection{The buffering effect of social support}

Although highly stressful situations are significant predictors of stress among humanitarian aid workers, research studies have shown considerable variability in reactions to critical incidents and exposure to stressors. The degree to which the individual is affected by a stressful situation may be linked to the availability of resources. Resources are defined as "objects, conditions, personal characteristics and energies that are either themselves valued for survival, directly or indirectly, or that serve as a means of achieving these ends" (Hobfoll, 1998, p.54). Some theories of stress and coping (e.g., Lazarus and Folkman, 1984) have highlighted the importance of buffering factors on the effects of stress among individuals. These factors can be individual resources (e.g., coping style, self-efficacy, competence) or work resources (e.g., work control, social support) (Sonnentag and Frese, 2003).

More specifically, some studies on humanitarian aid have suggested that social support and positive co-worker relationships may be of significant value to aid workers (e.g., Boscarino et al., 2004; Eriksson et al., 2009). For example, Boscarino et al. (2004) studied social workers who responded after the World Trade Center attacks. They found low levels of burnout and identified a negative relationship between burnout and work support. Cardozo et al. (2012) studied humanitarian aid workers providing help in emergencies. They found social support was associated with lower levels of psychological distress and greater life satisfaction. Furthermore, some non-profit organisations, which have the intent of improving the quality of management in humanitarian aid organisations, have underlined the importance of social support provided by group members and leaders (e.g., Buddy System, informal support groups, encouragement) to avoid stress (Antares Foundation, 2006; EFPA, 2011). Social support by co-workers and supervisors is often associated with reduced emotional exhaustion, increased energy and work commitment (Halbesleben, 2006; Vergara and Gardner, 2011). Despite intense work and chaotic environments, most members of humanitarian aid teams find ways of identifying accomplishments and finding energy through the support of the organisation, their supervisors and colleagues.

On the basis of these studies, we expected that the social support of colleagues and supervisors would moderate the effect of stress on TMSs. By reducing the negative reactions to stressful situations, strong social support would allow the development of transactive memory processes among humanitarian aid workers.

Hypothesis 2a: Social support would moderate the relationship between generic stress and transactive memory in humanitarian aid workers.

Hypothesis 2b: Social support would moderate the relationship between compassion fatigue and transactive memory in humanitarian aid workers.

\section{Methodology}

\subsection{Participants and procedure}

A total of 60 people who had provided disaster relief responded to the survey. There were 33 men $(55.2 \%)$ and 27 women (44.8\%), ranging in age from 18 to 60 years, with an average age of 34 years $(S D=10.94) ; 51.7 \%$ were married. Most had a post-graduate 
degree or higher $(55.2 \%)$ or a two-year university level $(27.6 \%)$. They had worked in humanitarian aid for an average of 6 years $(\min =1 ; \max =20 ; S D=5.35)$ and had worked with their non-governmental organisations (NGOs) for an average of 2 years $(\min =1 ; \max =9 ; S D=2)$, carrying out an average of three humanitarian aid missions $(\min =1 ; \max =45 ; S D=6.39)$.

This sample was composed only of expatriate humanitarian aid workers. They were mostly French nationals $(88.3 \%)$. The information they provided related to their most recent mission. They had worked in 18 different countries. The majority $(51.7 \%)$ had worked in Africa, $13.3 \%$ in Central/South America, $10 \%$ in Asia, $5 \%$ in the Middle East, $1.7 \%$ in Eastern Europe and $18.3 \%$ did not specify a location. Their missions included building and clearance operations, rescue operations, public health (linked to water, food and drought) and child and victim protection. The participants had different backgrounds: volunteers, NGO field officers and professional staff, students and fire-fighters.

The study was carried out between February 2010 and March 2011. The participants were contacted directly through their organisations or through social networks. They were sent the questionnaire by e-mail; an internet interface was created to make access easier. The questionnaire was available in French and English. When participants completed the questionnaire, they referred to their last intervention (e.g., "Please answer in relation to what you experienced during your last intervention") and the most recent team they had belonged to within the last few weeks (e.g., "Think about the work groups to which you currently belong. The items below ask about your relationship with your current team"). The questionnaire was completed anonymously and participants were ensured of the confidentiality of their responses.

\subsection{Measures}

Transactive memory. Transactive memory was measured using the scale developed in English by Lewis (2003). The reliability and validity of this scale have been demonstrated with different teams in various contexts and it has been translated into French (Michinov, 2007; Michinov et al., 2008). This scale contains 15 items (with minor modifications for the humanitarian aid context) related to the three dimensions of the TMS: specialisation (e.g., "I know which team members have expertise in specific areas"), coordination (e.g., "Our team worked together in a well-coordinated fashion") and credibility (e.g., "I was confident relying on the information that other team members brought to the discussion"). The mean of the entire scale was used, not those of the three dimensions, because of the small sample. Each item was scored on a 5-point Likert-type scale ranging from 1 (disagree strongly) to 5 (agree strongly). A number of items required reverse coding whereby higher scores on these subscales indicated higher transactive memory.

Perceived social support. Perceived social support was measured using eight items extracted from the Job Content Questionnaire (Karasek et al., 1998). The questionnaire included four items of social support from co-workers (e.g., "People I work with are competent in doing their jobs") and four items of social support from supervisors (e.g., "My supervisor shows concern for the well-being of the workers under his command"). A Likert-type scale ranging from 1 (disagree strongly) to 5 (agree strongly) was used. The participants referred to the last mission and the last team they belonged to. 
Generic stress. Generic stress was measured using the 10-item Perceived Stress Scale (PSS-10, Cohen and Williamson, 1988) (e.g., "In the last month, how often have you been upset because of something that happened unexpectedly?", "In the last month, how often have you felt that you were unable to control the important things in your life?"). The reliability and validity of this scale have been demonstrated in the literature and the French version has been widely accepted (Bellinghausen et al., 2009; Cousson-Gélie et al., 2005). Items were scored on a 5-point Likert-type scale ranging from 0 (never) to 4 (very often).

Compassion fatigue. Compassion fatigue was measured using the Professional Quality of Life scale (ProQOL-V, Stamm, 2010). This instrument is the fifth revision of the original compassion fatigue self-test survey developed by Figley (1995). We used 20 items from the two subscales relating to burnout and secondary traumatic stress (e.g., "I feel depressed because of the traumatic experiences of the people I help", "As a result of helping, I have intrusive, frightening thoughts"). We used the French translation (i.e., Stamm, 2009) with some minor modifications adapted to the humanitarian aid context. Items were scored using a 5-point Likert-type scale ranging from 1 (never) to 5 (very often).

The final section of the questionnaire covered socio-demographic details such as gender, age, level of education, job and status in the team. The questionnaire also included three additional items dealing with the number of years spent working in emergency humanitarian aid, the number of years worked with the last team and the number of assignments carried out with the current team.

\subsection{Statistical analyses}

To test the models, we used PLS analysis (Ringle et al., 2005), a soft modelling approach using a least-squares estimation procedure. Unlike covariance-based structural equation modelling (i.e., LISREL), PLS can be used with small samples (Chin, 1998), missing data and normal distribution of data. It can also be used to analyse field data (Sosik et al., 2009). We tested the models using the software package SmartPLS version 2.0.

First, we tested the measurement model to examine item reliability. The internal consistency was assessed by examining composite reliability (CR) (Chin, 2000) and Cronbach's Alpha (Cronbach, 1951). The convergent validity was assessed by examining the average variance extracted (AVE) (Fornell and Larcker, 1981), the significance and the size of item loadings on their respective constructs (Anderson and Gerbing, 1988). The discriminant validity was assessed by examining the cross-loading and the square root value of AVE, which should be greater than the correlation coefficients between the two constructs (Fornell-Larcker criterion).

Second, we tested the structural model: the relationship between stress (i.e., generic stress and compassion fatigue), perceived social support and transactive memory. The estimation and significance of the structural path coefficients were assessed using the bootstrapping procedure. Their significance was estimated using the $t$-statistic. In the present analyses, 200 bootstrap samples on 60 observations were analysed. To assess the quality of the global model, the relative amount of explained variance of the latent variables $\left(R^{2}\right)$ was examined (Cohen's $f 2$ ). The significance and weight of the structural path coefficients and the communality were also assessed. Figure 1 lists the results. 


\section{Findings}

\subsection{Measurement model}

A first analysis was conducted to examine item reliability. For this analysis, items should be dropped if they are insignificantly loaded with the intended construct, and item loadings should exceed 0.5 (Roussel et al., 2002). The initial analysis found that nine items for the transactive memory scale loaded lower than 0.5 , as well as four items for the perceived stress scale and nine items for the compassion fatigue scale. After dropping these items, all items were found to load significantly with the latent construct. Table 1 provides the loadings of each item to its intended construct and to all cross-loadings of other constructs.

Table 1 Cross-loadings and outer loadings

\begin{tabular}{|c|c|c|c|c|c|}
\hline & & $T M$ & $G S$ & $C F$ & $S S$ \\
\hline CO1. & Team members worked together in a well-coordinated fashion & $0.57 *$ & -0.02 & 0.10 & 0.47 \\
\hline $\mathrm{CO} 2$. & Our team had very few misunderstandings about what to do & $0.77 *$ & -0.28 & -0.25 & 0.27 \\
\hline CO4. & We accomplished the task smoothly and efficiently & $0.75 *$ & -0.23 & -0.08 & 0.53 \\
\hline CO5. & $\begin{array}{l}\text { There was much confusion about how we would accomplish } \\
\text { the task }\end{array}$ & $0.61 *$ & -0.46 & -0.59 & 0.20 \\
\hline CR3. & $\begin{array}{l}\text { I trusted that other members' knowledge about the project } \\
\text { was credible }\end{array}$ & $0.64 *$ & -0.07 & 0.10 & 0.40 \\
\hline CR5. & $\begin{array}{l}\text { I was confident relying on the information that other team } \\
\text { members brought to the discussion }\end{array}$ & $0.71 *$ & -0.22 & -0.30 & 0.42 \\
\hline SPE5. & I know which team members have expertise in specific areas & $0.51 *$ & -0.21 & -0.02 & 0.36 \\
\hline GS2. & $\begin{array}{l}\text { How often have you felt that you were unable to control the } \\
\text { important things in your life? }\end{array}$ & -0.20 & $0.60 *$ & 0.36 & 0.06 \\
\hline GS3. & How often have you felt nervous and 'stressed'? & -0.22 & $0.57 *$ & 0.43 & -0.26 \\
\hline GS6. & $\begin{array}{l}\text { How often have you found that you could not cope with all the } \\
\text { things that you had to do? }\end{array}$ & -0.19 & $0.63 *$ & 0.28 & -0.12 \\
\hline GS9. & $\begin{array}{l}\text { How often have you been angered because of things that were } \\
\text { outside of your control? }\end{array}$ & -0.16 & $0.67 *$ & 0.20 & -0.11 \\
\hline GS10. & $\begin{array}{l}\text { How often have you felt difficulties were piling up so high that } \\
\text { you could not overcome them? }\end{array}$ & -0.43 & $0.89 *$ & 0.59 & -0.07 \\
\hline BO3. & $\begin{array}{l}\text { I am not as productive at work because I am losing sleep over } \\
\text { the traumatic experiences of a person I help }\end{array}$ & -0.19 & 0.22 & $0.64 *$ & 0.01 \\
\hline BO4. & I feel trapped by my job as a humanitarian aid worker & -0.16 & 0.37 & $0.77 *$ & 0.00 \\
\hline BO7. & $\begin{array}{l}\text { Ifeel worn out because of my work as a humanitarian aid } \\
\text { worker }\end{array}$ & -0.14 & 0.28 & $0.55 *$ & -0.14 \\
\hline BO8. & Ifeel overwhelmed because my work load seems endless & -0.21 & 0.40 & $0.52 *$ & -0.00 \\
\hline BO9. & Ifeel 'bogged down' by the system & -0.43 & 0.59 & $0.75 *$ & -0.26 \\
\hline STS2. & I jump or am startled by unexpected sounds & -0.26 & 0.47 & $0.70 *$ & 0.07 \\
\hline STS4. & $\begin{array}{l}\text { I think that I might have been affected by the traumatic stress } \\
\text { of those I help }\end{array}$ & -0.20 & 0.50 & $0.82 *$ & 0.02 \\
\hline
\end{tabular}


Table 1 Cross-loadings and outer loadings (continued)

\begin{tabular}{llrrr}
\hline & $T M$ & $G S$ & $C F$ & $S S$ \\
\hline STS6. Ifeel depressed because of the traumatic experiences of the & -0.30 & 0.45 & $\mathbf{0 . 8 0}$ & -0.17 \\
& people I help & & \\
STS7. Ifeel as though I am experiencing the trauma of someone I & -0.16 & 0.43 & $\mathbf{0 . 7 8 *}$ & 0.02 \\
& have helped & & \\
STS8. I avoid certain activities or situations because they remind me & -0.16 & 0.33 & $\mathbf{0 . 6 9 *}$ & 0.01 \\
$\quad$ of the frightening experiences of the people I help & & & & \\
SSS1. Supervisor is concerned & 0.30 & -0.14 & 0.04 & $\mathbf{0 . 7 5 *}$ \\
SSS2. Supervisor pays attention & 0.30 & -0.16 & -0.08 & $\mathbf{0 . 6 8 *}$ \\
SSS4. Helpful supervisor & 0.40 & -0.08 & 0.03 & $\mathbf{0 . 8 4 *}$ \\
SSS5. Supervisor good organiser & 0.40 & -0.05 & -0.01 & $\mathbf{0 . 8 2 *}$ \\
CSS1. Co-workers competent & 0.43 & -0.06 & 0.07 & $\mathbf{0 . 5 6 *}$ \\
CSS2. Co-worker interested in me & 0.46 & -0.13 & -0.29 & $\mathbf{0 . 7 1 *}$ \\
CSS3. Friendly co-workers & 0.28 & -0.10 & -0.14 & $\mathbf{0 . 5 5 *}$ \\
CSS5. Co-workers helpful & 0.39 & -0.05 & -0.13 & $\mathbf{0 . 7 3 *}$ \\
\hline
\end{tabular}

*Outer loadings; $\mathrm{TM}=$ transactive memory; $\mathrm{GS}=$ generic stress; $\mathrm{CF}=$ compassion fatigue; $\mathrm{SS}=$ social support; $\mathrm{CO}=$ coordination; $\mathrm{CR}=$ credibility; $\mathrm{SPE}=$ specialisation; $\mathrm{BO}=$ burnout; STS = secondary traumatic stress; SSS = supervisor social support; $\mathrm{CSS}=$ co-worker social support.

Second, convergent validity was assessed by examining composite reliability (CR) and the AVE; results are reported in Table 2. All AVE values exceed 0.5 and the CR values were greater than 0.6, demonstrating adequate convergent validity (Bagozzi and Yi, 1988). Moreover, Cronbach's values exceeded the recommended value of 0.6 , indicating adequate item reliability (Nunnally, 1978). Third, we examined discriminate validity following the criteria suggested by Fornell and Larcker (1981); the AVE of each construct were higher than the squared correlations with all constructs (Table 2). Moreover, the loading of each indicator was greater than all of its cross-loading (Table 1) (Chin, 1998). These two points demonstrated the discriminant validity of the latent constructs used in this study. In sum, these analyses suggested the acceptability of the measurement model.

Table 2 Average variance extracted (AVE), composite reliability, Cronbach's alpha, latent variable correlations and square root values of $\mathrm{AVE}$

\begin{tabular}{|c|c|c|c|c|c|c|c|}
\hline \multirow[b]{2}{*}{ Measures } & \multirow{2}{*}{$\begin{array}{c}A V E \\
(>0.50)\end{array}$} & \multirow{2}{*}{$\begin{array}{c}\text { Composite } \\
\text { reliability }(>0.70)\end{array}$} & \multirow{2}{*}{$\begin{array}{l}\text { Cronbach's } \\
\text { alpha }(>0.70)\end{array}$} & \multicolumn{4}{|c|}{$\begin{array}{l}\text { Latent variable correlations } \\
\text { and square root values of } A V E\end{array}$} \\
\hline & & & & 1 & 2 & 3 & 4 \\
\hline $\begin{array}{l}1 \text { Transactive } \\
\text { memory }\end{array}$ & 0.43 & 0.84 & 0.79 & $0.66^{*}$ & & & \\
\hline 2 Generic stress & 0.46 & 0.81 & 0.71 & -0.39 & $0.68^{*}$ & & \\
\hline $\begin{array}{l}3 \text { Compassion } \\
\text { fatigue }\end{array}$ & 0.50 & 0.91 & 0.89 & -0.35 & 0.61 & $0.70^{*}$ & \\
\hline 4 Social support & 0.51 & 0.89 & 0.86 & 0.54 & -0.13 & -0.10 & $0.71^{*}$ \\
\hline
\end{tabular}

*Square root values of AVE. 


\subsection{Structural model}

Figure 1 is a graphical representation of the PLS results, and Table 3 contains the loadings of the items on each construct.

Figure 1 The structural model (see online version for colours)

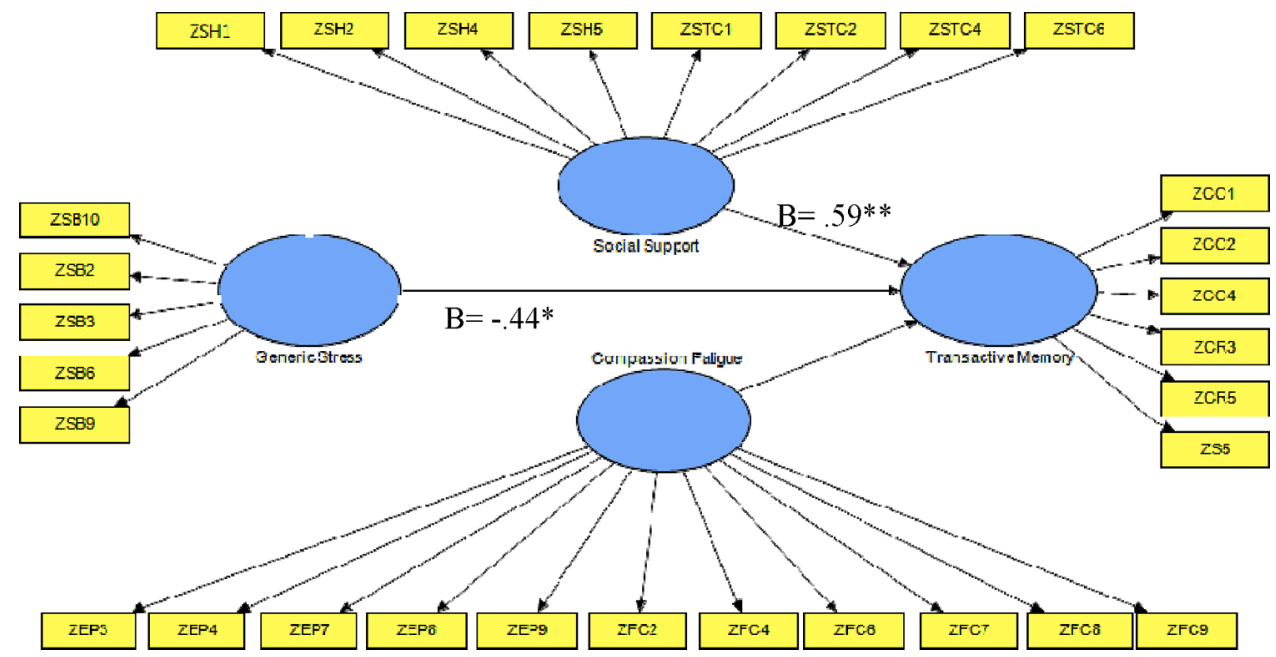

Table 3 Direct effects

\begin{tabular}{lccc}
\hline Measures & $\beta$ & $t$ & $p$ \\
\hline Effect of GS on TM & -0.44 & 2.82 & 0.01 \\
Effect of CF on TM & -0.70 & 1.29 & N.S. \\
Effect of SS on TM & 0.59 & 8.69 & 0.001 \\
\hline
\end{tabular}

$\mathrm{GS}=$ generic stress; $\mathrm{TM}=$ transactive memory; $\mathrm{CF}=$ compassion fatigue; $\mathrm{SS}=$ social support.

As predicted in Hypothesis 1a, generic stress was negatively related to transactive memory among humanitarian aid workers $(\beta=-0.44, t=2.82, p<0.01)$. However, compassion fatigue was not related to transactive memory $(\beta=-0.70, t=1.29)$. Contrary to our Hypothesis $1 \mathrm{~b}$, compassion fatigue had no significant impact on transactive memory among humanitarian aid workers. Applying the appreciation criteria of Cohen (1977), the determination coefficient of the transactive memory variable was higher $\left(R^{2}=0.42\right)$. Furthermore, perceived social support positively predicted transactive memory $(\beta=0.59, t=8.69, p<0.001)$.

\subsection{Tests of the moderation model}

We tested the moderating effect of social support on the relationship between generic stress and transactive memory using the product term approach (Henseler and Chin, 2010; Henseler and Fassott, 2010), adding an additional latent variable in the structural model covering the product of the moderator variable and the independent variable. 
To determine the significance of the moderating effect, we compared the determination coefficients $R^{2}$ of the models with and without moderator effects.

This model was not accepted. Contrary to our Hypothesis 2a, the interaction effect of generic stress and perceived social support on transactive memory among humanitarian aid workers was not significant $(\beta=-0.34, t=0.89$ ). Moreover, the relationship between generic stress and transactive memory was not significant $(\beta=-0.22, t=1.68)$. As there was no significant relationship between compassion fatigue and transactive memory constructs, we could not test this second moderation model. Finally, our hypothesis of the moderating role of social support was not supported.

\section{Discussion}

This study aimed to examine coordination processes (transactive memory) and, more especially, the relationships between stress, social support and TMSs among a specific community: expatriate humanitarian aid workers.

First, the results of the measurement model provide evidence that there are specific TMSs among humanitarian aid workers. Transactive memory was found to be essentially based on coordination and credibility; only one item of the coordination component and two items of the credibility component were dropped. This supports findings that humanitarian aid workers develop specific coordination processes (Majchrzak et al., 2007), including informal practices such as dialogic coordination or learning-by-doing (Faraj and Xiao, 2006; Tierney et al., 2001).

Humanitarian aid workers trust the task expertise of their co-workers. This supports the findings of Tatham and Kovács (2005) that members of humanitarian aid teams develop swift trust based on action and inference processes. However, expertise specialisation seems to have difficulty developing. Indeed, in such volatile environments, it is often difficult to identify experts and assign tasks based on expertise. Unstable environments and emergency work also lead to less well-defined and clear-cut roles. Moreover, humanitarian aid workers are very mixed: some are highly skilled and trained (e.g., programme coordinators, fire-fighters, nurses), others less so (e.g., volunteers, students). Consequently, the role of expertise specialisation in TMSs must be reconceptualised within humanitarian aid teams. We need to consider not only the expertise and knowledge of each co-worker, but also their ability to contribute to and access resources, and to develop knowledge flexibility and general skills.

Moreover, the results of the structural model provide support for the hypothesis of a negative relationship between stress and transactive memory. On the basis of theoretical formulations derived from the emergent coordination processes, we expected that stress related to organisational aspects in teams (generic stress) would be negatively related to TMSs among humanitarian aid workers. This prediction was confirmed by our results, supporting the previous research showing that stress has a negative and sometimes disastrous impact in teams (e.g., Driskell et al., 1999; Entin and Serfaty, 1999). Indeed, stressful situations can lead team members to move from a team-focused to a personfocused perspective, consequently disrupting team activities, such as coordination and shared knowledge including mental models or transactive memory (e.g., Ellis, 2006; Pearsall et al., 2009). This negative effect of stress on transactive memory was not observed with compassion fatigue. Several explanations for this absence of relationship can be put forward. First, it could be due to the different sources of stressors for generic 
stress and compassion fatigue. The main stressor for generic stress in humanitarian aid arises from difficult relationships between co-workers or with the supervisor (e.g., Bierens de Haan, 1995; Bierens de Haan et al., 2002). This specific form of stress is thus directly related to interpersonal relationships, coordination conflict and shared knowledge among humanitarian aid staff. This could explain the negative relationship between generic stress and coordination processes, such as transactive memory. On the other hand, compassion fatigue can be caused by work overload, frequent contact with victims and the inability to meet their needs and is directly linked to the cost of caring for people (Figley, 1995) rather than to team dynamics and coordination processes. This could explain the lack of relationship between compassion fatigue and transactive memory.

Our second hypothesis is not supported by the results; perceived social support among humanitarian aid workers did not moderate the negative effect of generic stress on transactive memory. Three main explanations can be proposed. First, social support may not be sufficient to moderate the negative effect of stress on transactive memory. The humanitarian aid sector is characterised by a lack of a number of resources (e.g., time, information, personnel and equipment), which can be a source of stress, and the social support may not be sufficient to attenuate this effect. Second, other factors may help aid workers to maintain well-being and efficient coordination practices under stressful situations. For example, Vergara and Gardner (2011) have demonstrated the importance of personality variables such as cognitive hardiness, self-efficacy and coping mechanisms. Work variables (e.g., workload, clarity of role) should also be studied. A third explanation is that the measure of social support used in this study is inappropriate for a sample of humanitarian aid workers as some items were taken from Karasek et al.'s (1998) scale, initially designed for organisational settings. Future studies are needed to develop specific tools to study social support in the humanitarian aid domain.

\subsection{Limitations}

This study has some limitations. First, the sample was small and was mainly composed of French aid workers. Further studies with larger samples and with aid workers from different cultural backgrounds are needed. Because of their potential impact on stress and coordination processes, background differences (i.e., expertise, experience) among humanitarian aid workers should also be considered. The second major limitation is the cross-sectional, self-report data, which do not allow causal inferences to be drawn; the PLS and bootstrap analyses can be used to examine relationships between measures among small samples, but larger samples are required to test the measurement model. Moreover, this study shows no distinction between short- and long-term consequences of stress on coordination. Further studies using longitudinal designs should be carried out to assess the effect of stress on coordination processes over time. Third, we tested the validity of the scales in a small sample of expatriate humanitarian aid workers. Even though our model had a good fit with selected items in this study, we had to drop some items of transactive memory, generic stress and compassion fatigue scales. Further studies with a new sample are needed to explore the psychometric properties of the scales (i.e., test-retest reliability, criterion validity and responsiveness) for the humanitarian field. 


\subsection{Implications for practice}

Despite these limitations, the results of this study provide additional information about coordination processes in humanitarian aid teams, and support our hypotheses of a negative relationship between transactive memory and generic stress. This highlights the need to manage humanitarian aid workers' stress. More specifically, our results demonstrate the importance for aid organisation managers and coordinators to create a "positive work climate for their co-workers" (Musa and Hamid, 2008, p.415). Generic stress is directly related to interpersonal relationships, which may cause coordination conflict among humanitarian aid workers. Two types of programmes could be used to foster this positive work environment and reduce generic stress: team-skills training before the mission, and psychological support during the mission. Before missions, training programmes could be constructed to develop non-technical skills among humanitarian aid workers. Non-technical skills include the social and cognitive skills involved in sharing situation awareness, decision-making, communication, leadership, teamwork and stress and fatigue management (Flin et al., 2008). Such training programmes already exist, based on the principles of crew resource management (CRM), which was originally developed for the aviation sector (Kanki et al., 2010) and then applied to other areas such as the medical sector (Fletcher et al., 2004). It would be interesting to develop specific training programmes for the humanitarian aid sector. During the mission, specific actions should also be carried out to reduce generic stress and enhance coordination among foreign humanitarian aid workers. Yanay et al. (2011) specifically stressed the need for informal meetings and communication at different levels (between managers, intra- and inter-teams) during the mission, for two main reasons. First, informal gatherings provide the social support required by humanitarian aid workers. Second, they allow co-workers to get to know each other, to exchange information and to develop interpersonal skills that enhance implicit coordination. This should allow humanitarian aid teams to maintain their performance under stress. In Yanay et al.'s (2011) study, only teams that switched from explicit to implicit coordination performed successfully.

Finally, this study underlines the need to develop research specialising in the study of coordination processes and shared knowledge in humanitarian aid teams. Few studies have investigated the specific coordination processes and integration of knowledge in emergent response groups (Drabek, 1986). Nevertheless, investigation of coordination and knowledge-sharing processes is a major issue for the well-being and efficacy of humanitarian aid workers. It would be an important contributor to the ability to respond rapidly to disasters and to set up emergency aid.

\section{References}

Akgün, A.E., Lynn, G.S. and Yılmaz, C. (2006) 'Learning process in new product development teams and effects on product success: a socio-cognitive perspective', Industrial Marketing Management, Vol. 35, No. 2, pp.210-224.

Anderson, J.C. and Gerbing, D.W. (1988) 'Structural equation modeling in practice: a review and recommended two-step approach', Psychological bulletin, Vol. 103, No. 3, pp.411-423.

Antares Foundation (2006) Managing Stress in Humanitarian Aid Workers. Guideline for Good Practice, Available at: http://www.antaresfoundation.org/download/strategies_de reduction_des_risques.pdf 
Bagozzi, R.P. and Yi, Y. (1988) 'On the evaluation of structural equation models', Journal of Academy of Marketing Science, Vol. 16, No. 1, pp.74-94.

Bellinghausen, L., Collange, J., Botella, M., Emery, J-L. and Albert, E. (2009) 'Validation factorielle de l'échelle française de stress perçu en milieu professionnel', Santé Publique, Vol. 21, No. 4, pp.365-373.

Bierens de Haan, B. (1995) 'L'importance de la prévention du stress dans l'engagement humanitaire en zone de conflits', Revue suisse de médecine militaire et de catastrophes, Vol. 72, pp.5-11.

Bierens de Haan, B., Van Beerendonk, H., Michel, N. and Mulli, J-C. (2002) 'Le programme de soutien psychologique des intervenants humanitaires du Comité International de la CroixRouge (CICR)', Revue Française de Psychiatrie et de Psychologie Médicale, Vol. 6, No. 53. Available online at: http://www.icrc.org/fre/resources/documents/misc/5fzjgf.htm

Boscarino, J.A., Figley, C.R. and Adams, R.E. (2004) 'Compassion fatigue following the September 11 terrorist attacks: a study of secondary trauma among New York City social workers', International Journal of Emergency Mental Health, Vol. 6, No. 2, pp.57-66.

Cardozo, B.L., Crawford, C.G., Eriksson, C., Zhu, J., Sabin, M., Ager, A., Foy, D., Snider, L., Scholte, W., Kaiser, R., Olff, R., Rijnen, B. and Simon, W. (2012) 'Psychological distress, depression, anxiety, and burnout among international humanitarian aid workers: a longitudinal study', PLOS ONE, Vol. 7, No. 9, p.e44948.

Carlile, P.R. (2002) 'A pragmatic view of knowledge and boundaries: Boundary objects in new product development', Organization Science, Vol. 13, No. 4, pp.442-455.

Chin, W.W. (1998) 'The partial least squares approach for structural equation modeling', in Marcoulides, G.A. (Ed): Modern Methods for Business Research, Lawrence Erlbaum Associates, Mahwah, New-Jersey, pp.294-336.

Chin, W.W. (2000) 'Partial least squares for IS researchers: an overview and presentation of recent advances using the PLS approach', Proceedings of the 21st International Conference on Information Systems, Brisbane, Australia. Available at: http://disc-nt.cba.uh.edu/chin/ icis2000plstalk.pdf

Cohen, J. (1977) Statistical Power Analysis for the Behavioral Sciences, Lawrence Erlbaum Associates, New York.

Cohen, S. and Williamson, G. (1988) 'Perceived stress in a probability sample of the US', in Spacapam, S. and Oskamp, S. (Eds.): The Social Psychology of Health: Claremont Symposium on Applied Social Psychology, Sage, Newbury Park, CA, pp.31-67.

Cousson-Gélie, F., Bruchon-Schweitzer, M., Dilhuydy, J.M., Irachabal, S. and Lakdja, F. (2005) 'Impact du contrôle perçu, de l'attribution causale interne et du contrôle religieux sur la qualité de vie et l'évolution de la maladie de patientes atteintes d'un premier cancer du sein', Revue francophone de psycho-oncologie, Vol. 4, No. 4, pp.288-291.

Cronbach, L.J. (1951) 'Coefficient alpha and the internal structure of tests', Psychometrika, Vol. 16, No. 3, pp.297-334.

Drabek, T.E. (1986) Human System Responses to Disaster: An Inventory of Sociological Findings, Springer-Verlag, New York, NY.

Drabek, T.E. and McEntire, D.A. (2003) 'Emergent phenomena and the sociology of disaster: Lessons, trends and opportunities from the research literature', Disaster Prevention and Management, Vol. 12, No. 2, pp.97-112.

Driskell, J.E. and Salas, E. (1991) 'Group decision making under stress', Journal of Applied Psychology, Vol. 76, No. 3, pp.473-478.

Driskell, J.E., Salas, E. and Johnston, J. (1999) 'Does stress lead to a loss of team perspective?', Group Dynamics: Theory, Research, and Practice, Vol. 3, No. 4, pp.291-302.

EFPA (2011) Disaster, Crisis and Trauma Psychology: Introduction, European Federation of Psychologists' Associations, Available at: http://disaster.efpa.eu/

Ehrenreich, J.H. and Elliott, T.L. (2004) 'Managing stress in humanitarian aid workers', Peace and Conflict: Journal of Peace Psychology, Vol. 10, No. 1, pp.53-66. 
Ellis, A.P. (2006) 'System breakdown: the role of mental models and transactive memory in the relationship between acute stress and team performance', The Academy of Management Journal, Vol. 49, No. 3, pp.576-589.

Entin, E.E. and Serfaty, D. (1999) 'Adaptive team coordination', Human Factors: The Journal of the Human Factors and Ergonomics Society, Vol. 41, No. 2, pp.312-325.

Eriksson, C.B., Bjorck, J.P., Larson, L.C., Walling, S.M., Trice, G.A., Fawcett, J., Abernethy, A.D. and Foy, D.W. (2009) 'Social support, organisational support, and religious support in relation to burnout in expatriate humanitarian aid workers', Mental Health, Religion and Culture, Vol. 12, No. 7, pp.671-686.

Faraj, S. and Sproull, L. (2000) 'Coordinating expertise in software development teams', Management Science, Vol. 46, No. 12, pp.1554-1568.

Faraj, S. and Xiao, Y. (2006) 'Coordination in fast-response organizations', Management science, Vol. 52, No. 8, pp.1155-1169.

Figley, C.R. (Ed.) (1995) Compassion Fatigue: Coping with Secondary Traumatic Stress Disorder in Those Who Treat the Traumatized, Brunner-Routledge, New York, NY.

Fletcher, G., Flin, R., McGeorge, P., Glavin, R., Maran, N. and Patey, R. (2004) 'Rating nontechnical skills: developing a behavioural marker system for use in anaesthesia', Cognition, Technology and Work, Vol. 6, pp.165-171.

Flin, R., O'Connor, P. and Crichton, D.M. (2008) Safety at the Sharp End: A Guide to NonTechnical Skills, Ashgate, Aldershot, UK.

Fornell, C. and Larcker, D.F. (1981) 'Evaluating structural equation models with unobservable variables and measurement error', Journal of marketing research, Vol. 18, No. 1, pp.39-50.

Halbesleben, J.R. (2006) 'Sources of social support and burnout: a meta-analytic test of the conservation of resources model', Journal of applied Psychology, Vol. 91, No. 5, pp.1134-1145.

Henseler, J. and Chin, W.W. (2010) 'A comparison of approaches for the analysis of interaction effects between latent variables using partial least squares path modeling', Structural Equation Modeling, Vol. 17, No. 1, pp.82-109.

Henseler, J. and Fassott, G. (2010) 'Testing moderating effects in PLS path models: an illustration of available procedures', in Esposito, V., Chin, W.W., Henseler, J. and Wang, H. (Eds.): Handbook of Partial Least Squares, Springer-Verlag, Berlin/Heidelberg, pp.713-735.

Hobfoll, S.E. (1998) Stress, Culture, and Community: The Psychology and Philosophy of Stress, Plenum, New York, NY.

Hollingshead, A.B. (1998) 'Distributed knowledge and transactive processes in decision-making groups', in Neale, M.A., Mannix, E.A. and Gruenfeld, D.H. (Eds.): Research on Managing Groups and Teams, JAI Press, Grennwich, CT, Vol. 1, pp.103-123.

Jehn, K.A., Northcraft, G.B. and Neale, M.A. (1999) 'Why differences make a difference: a field study of diversity, conflict and performance in workgroups', Administrative Science Quarterly, Vol. 44, No. 4, pp.741-763.

Kanki, B.G., Helmreich, R.L. and Anca, J. (2010) Crew Resource Management, Academic Press, San Diego, CA.

Karasek, R., Brisson, C., Kawakami, N., Houtman, I., Bongers, P. and Amick, B. (1998) 'The job content questionnaire (JCQ): an instrument for internationally comparative assessments of psychosocial job characteristics', Journal of Occupational Health Psychology, Vol. 3, No. 4, pp.322-355.

Lazarus, R.S. and Folkman, S. (1984) Stress, Appraisal, and Coping, Springer, New York.

Leedom, D.K. and Simon, R. (1995) 'Improving team coordination: a case for behavior-based training', Military Psychology, Vol. 7, No. 2, pp.109-122.

LePine, J.A., LePine, M.A. and Jackson, C.L. (2004) 'Challenge and hindrance stress: relationships with exhaustion, motivation to learn, and learning performance', Journal of Applied Psychology, Vol. 89, No. 5, pp.883-891. 
Lewis, K. (2003) 'Measuring transactive memory systems in the field: scale development and validation', Journal of Applied Psychology, Vol. 88, No. 4, pp.587-604.

Liang, D.W., Moreland, R. and Argote, L. (1995) 'Group versus individual training and group performance: the mediating role of transactive memory', Personality and Social Psychology Bulletin, Vol. 21, No. 4, pp.384-393.

Majchrzak, A., Jarvenpaa, S. and Hollingshead, A.B. (2007) 'Coordinating expertise among emergent groups responding to disasters', Organization Science, Vol. 18, No. 1, pp.147-161.

Michinov, E. (2007) 'Validation de l'échelle de mémoire transactive en langue française et adaptation au contexte académique', Revue Européenne de Psychologie Appliquée, Vol. 57, No. 1, pp.59-68.

Michinov, E., Olivier-Chiron, E., Rusch, E. and Chiron, B. (2008) 'Influence of transactive memory on perceived performance, job satisfaction and identification in anaesthesia teams', British journal of anaesthesia, Vol. 100, No. 3, pp.327-332.

Moreland, R.L. (1999) 'Transactive memory: Learning who knows what in work groups and organizations', in Thompson, L.F., Levine, J.M. and Messick, D. (Eds.): Shared Cognition in Organizations: The Management of Knowledge, Lawrence Erlbaum, Mahwah, NJ, pp.3-31.

Moreland, R.L. and Argote, L. (2003) 'Transactive memory in dynamic organizations', in Peterson, R.S. and Mannix, E.A. (Eds.): Leading and Managing People in the Dynamic Organization, Lawrence Erlbaum, Mahwah, NJ, pp.135-162.

Moreland, R.L. and Myaskovsky, L. (2000) 'Exploring the performance benefits of group training: Transactive memory or improved communication?', Organizational Behavior and Human Decision Processes, Vol. 82, No. 1, pp.117-133.

Moreland, R.L., Argote, L. and Khrisnan, R. (1996) 'Socially shared cognition at work: transactive memory and group performance', in Nye, J.L. and Brower, A.M. (Eds.): What's Social about Social Cognition? Research on Socially Shared Cognition in Small Groups, Sage, Thousand Park, CA, pp.57-84.

Musa, S.A. and Hamid, A.A.R. (2008) 'Psychological problems among aid workers operating in Darfur', Social Behavior and Personality: An International Journal, Vol. 36, No. 3, pp.407-416.

Nunnally, J.C. (1978) Psychometric Theory, 2nd ed., McGraw-Hill, New York, NY.

Pearsall, M.J., Ellis, A.P.J. and Stein, J.H. (2009) 'Coping with challenge and hindrance stressors in teams: behavioral, cognitive, and affective outcomes', Organizational Behavior and Human Decision Processes, Vol. 109, No. 1, pp.18-28.

Prati, G., Pietrantoni, L. and Cicognani, E. (2010) 'Self-efficacy moderates the relationship between stress appraisal and quality of life among rescue workers', Anxiety, Stress, \& Coping, Vol. 23, No. 4, pp.463-470.

Ren, Y., Carley, K.M. and Argote, L. (2006) 'The contingent effects of transactive memory: When is it more beneficial to know what others know?', Management Science, Vol. 52, No. 1, pp.671-682.

Resnick, L.B., Levine, J.M. and Teasley, S.D. (Eds.) (1991) Perspectives on Socially Shared Cognition, American Psychological Association, Washington DC.

Rico, R., Sánchez-Manzanares, M., Gil, F. and Gibson, C. (2008) 'Team implicit coordination processes: a team knowledge-based approach', The Academy of Management Review, Vol. 33, No. 1, pp.163-184.

Ringle, C., Wende, S. and Will, A. (2005) SmartPLS 2.0 (Beta), Hamburg, www.smartpls.de

Roussel, P., Durrieu, F., Campoy, E. and El Akremi, A. (2002) Méthodes d'équations structurelles: recherche et applications en gestion, Economica, Paris, France.

Serfaty, D. and Entin, E.E. (1977) Decision Making Under Stress: Emerging Themes and Applications, Ashgate, Aldershot, UK. 
Sonnentag, S. and Frese, M. (2003) 'Stress in organizations', in Borman, W.C., Ilgen, D.R. and Klimoski, R.J. (Eds.): Comprehensive Handbook of Psychology, Wiley, Hoboken, NJ, Vol. 12, pp.453-491.

Sosik, J.J., Kahai, S.S. and Piovoso, M.J. (2009) 'Silver bullet or voodoo statistics?', Group and Organization Management, Vol. 34, No. 1, pp.5-36.

Stamm, B.H. (1995) Secondary Traumatic Stress: Self-Care Issues for Clinicians, Researchers, and Educators, The Sidran Press, Baltimore, MD.

Stamm, B.H. (2009) Echelle de Qualité de Vie Professionnelle (ProQOL), Satisfaction pour la compassion et usure de la compassion. Available at: http://www.proqol.org/uploads/ProQOL5_French.pdf

Stamm, B.H. (2010) The Concise ProQOL Manual, Pocatello, ID, Available at: http://proqol.org/ uploads/ProQOL_Concise_2ndEd_12-2010.pdf

Stephenson, M. (2005) 'Making humanitarian relief networks more effective: operational coordination, trust and sense making', Disasters, Vol. 29, No. 4, pp.337-350.

Tatham, P. and Kovács, G. (2010) 'The application of 'swift trust' to humanitarian logistics', International Journal of Production Economics, Vol. 126, No. 1, pp.35-45.

Tierney, K.J., Lindell, M.K. and Perry, R.W. (2001) Facing the Unexpected: Disaster Preparedness and Response in the United States, Joseph Henry Press, Washington DC.

Vergara, J.A. and Gardner, D. (2011) 'Stressors and psychological wellbeing in local humanitarian workers in Colombia', Journal of Managerial Psychology, Vol. 26, No. 6, pp.500-507.

Wegner, D.M. (1987) 'Transactive memory: a contemporary analysis of the group mind', in Mullen, B. and Goethals, G.R. (Eds.): Theories of Group Behavior, Springer, New York, NY, pp.185-208.

Wegner, D.M., Erber, R. and Raymond, P. (1991) 'Transactive memory in close relationships', Journal of Personality and Social Psychology, Vol. 61, No. 6, pp.923-929.

Yanay, U., Benjamin, S. and Yamin, H.G. (2011) 'Networking emergency teams in Jerusalem', Disasters, Vol. 35, No. 1, pp.183-199. 